\title{
Comparison Of Different DC Motor Modeling Techniques
}

\author{
Farzin Asadi ${ }^{1}$ Kei Eguchi ${ }^{2}$ \\ 1. Mechatronics engineering department, Kocaeli university, Kocaeli, Turkey. \\ 2. Department of information electronics, Fukuoka institute of technology, Fukuoka, Japan.
}

\begin{abstract}
A DC motor is the most widely used actuator in the industry, especially for robotic applications such as position control of robot manipulators. When motor is used in high performance close loop motion control systems, an accurate model of motor is required for control system design ${ }^{[1,2]}$. Mathematical description of DC motor is divided into two subsystems: Electrical and mechanical subsystems. Electrical subsystem of a DC motor is simple. It consist of a resistor, an inductor and a back-EMF source. Nowadays, digital RLC meters can be found in nearly all labs. This paper study the reliability of model obtained by using a digital RLC meter. Results shows that although RLC meters can measure impedances easily and quickly, obtained values are not precious because RLC meter's output current is in the range of $\mathrm{mA}$ while motor works with several Ampers.
\end{abstract}

Key words: DC motor; electrical machines; modeling; motion control systems

Corresponding author: Farzin Asadi, E-mail: farzin.asadi@,kocaeli.edu.tr

\section{Introduction}

A DC motor is a rotary machine that converts DC currents into mechanical energy. DC motors can be divided into different types although their working principles are the same. DC motor types are: Brushed, brushless and un commutated. Transferring energy from outside world to the spinning rotor is done via carbon brushes and commutators. Brushed DC motors have advantages like: High reliability, low cost and simple control of motor speed. Disadvantages are high maintenance requirement which is cleaning or replacing the carbon brushes and commutators. Brushless DC motors have no such problems. Brushless motor's rotor is composed of one or more permanent magnets. Stator is composed of an electromagnets. Rotor position is sensed with the aid of Hall effect sensor. Based on the information taken from the sensors, controller decides to activate the required electromagnets. Brushless motors advantages are: High efficiency, little or no maintenance, better speed versus torque characteristic, high speed ranges and long life span. Disadvantages are: High motor cost, more complicated motor speed controller (Motor is driven bay a DC/AC converter). Un commutated motors require no commutation. They can be categorized as: Homopolar and ball bearing motors. Both, have restricted practical applications. Homopolar motors, can operate with very low level voltages. Despite of aforementioned disadvantages brushed DC motors have wide application range. Some, typical examples are robotics and electric locomotives. Developing a close loop control system for this type of motors requires the dynamical model of motor. Nowadays, digital RLC meters can be found in nearly all labs. Extraction of DC motor's model using a digital RLC meter is the aim of this paper. Digital RLC meter's output provides a low level current in the range of $\mathrm{mA}$. Motor's working condition, i.e. current in motor' $\mathrm{s}$ winding, is too different, in the range of Ampers. This paper want to answer this question: "Does the model extracted using a digital RLC meter coincide with model obtained using other methods?".This paper is organized as follows: DC motor's model is introduced in the second section. Laboratory results are given in the third section and finally conclusion are drawn. 
The electric equivalent circuit of the armature and free body diagram of the rotor is shown in Fig.1:

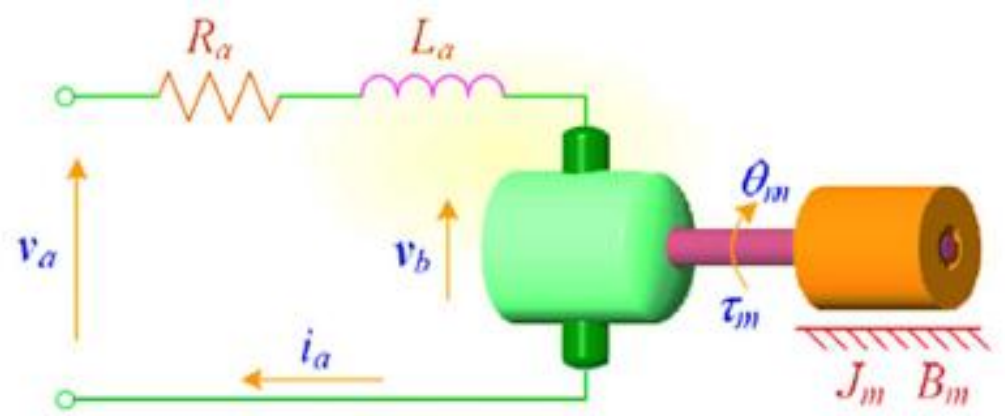

Fig.1 Schematic Representation of a DC Motor System

Using Newton's second law and Kirchhohff's Voltage Law $(\mathrm{KVL})$ one can write:

$$
\begin{aligned}
& J_{m} \frac{d^{2} \theta}{d t^{2}}=\tau(t)-B_{m} \frac{d \theta}{d t} \\
& L_{a} \frac{d i_{a}}{d t}=v_{a}(t)-R_{a} i_{a}(t)-v_{b}(t)
\end{aligned}
$$

Where $J_{m}, \theta, \tau, B_{m}, L_{a}, R_{a}, i_{a}, v_{a}$ and $v_{b}$ shows moment of inertia, angle of motor's shaft, developed torque, friction coefficient, armature inductance, armature resistance, armature current, input voltage and back EMF voltage, respectively.

Using Laplace transform, $\frac{\omega(s)}{v_{a}(s)}=$ $\frac{k_{a}}{\left.\left(L_{a} s+R_{a}\right) U_{m} s+B_{m}\right)+k_{a} k_{b}}$. Where $k_{a}$ and $k_{b}$ shows torque constant and back EMF constant, respectively. Fig. 2, shows the feedback block diagram of a DC motor.

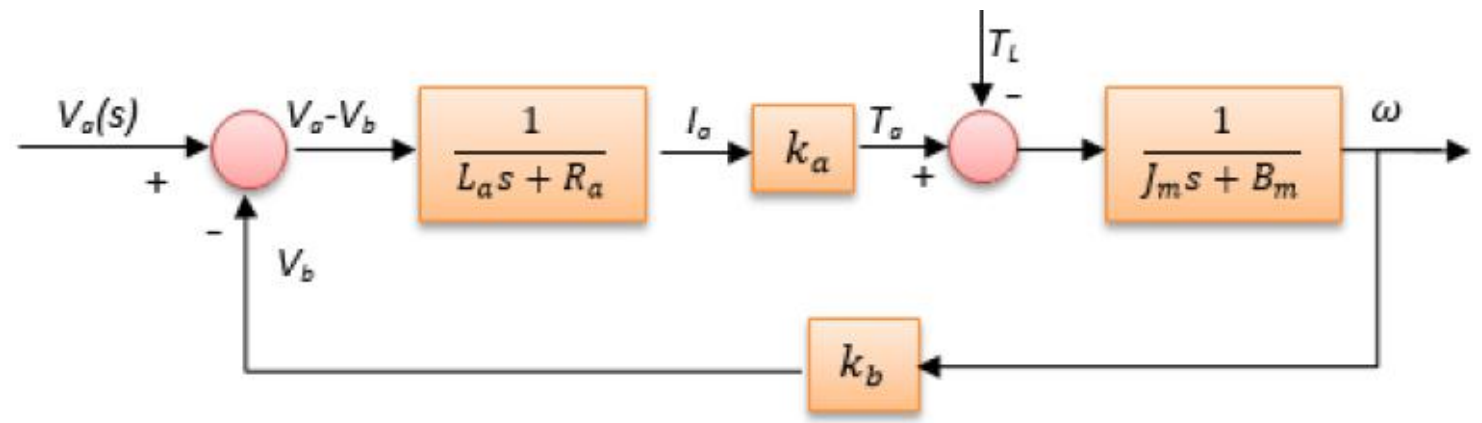

Fig.2 Block Diagram of DC Motor

\section{Laboratory Results}

Under test DC motor is shown in Fig.3:

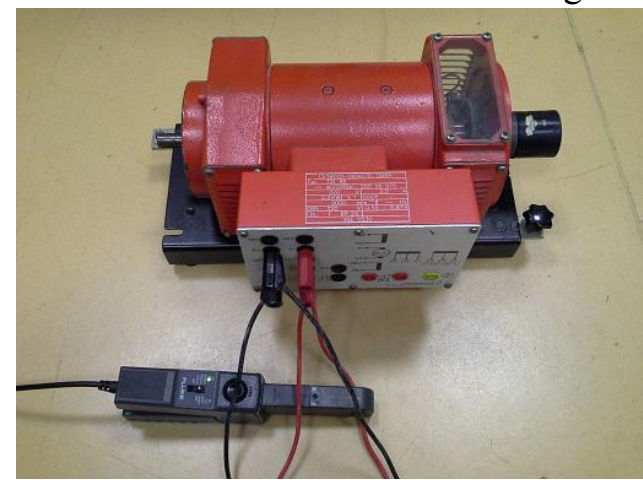

Fig.3 Motor under Test

Motor is used as a separately excited machine. Field current is set to $0.25 \mathrm{~A}$. When a digital RLC meter is connected to armature winding, $\mathrm{L}=107.3 \mathrm{mH}$ and $\mathrm{r}=$ $6.9221 \Omega$ is measured.

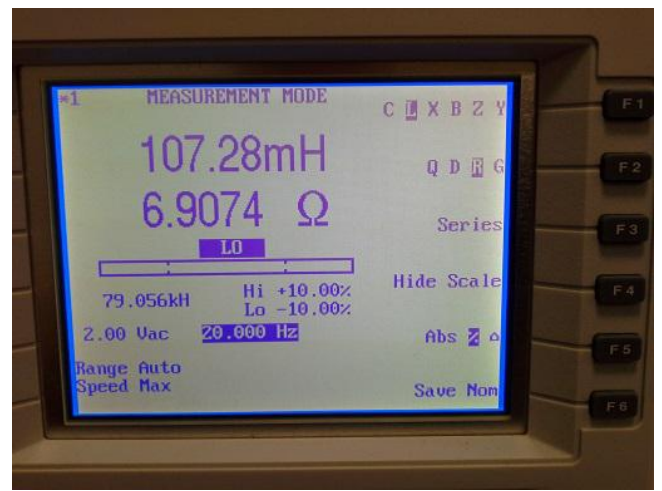

Fig.4 Impedance of Armature Winding as Seen by RLC Meter $(\mathrm{f}=20 \mathrm{~Hz})$ 
Voltage waveform across the armature winding during the measurement is shown in Fig.5:

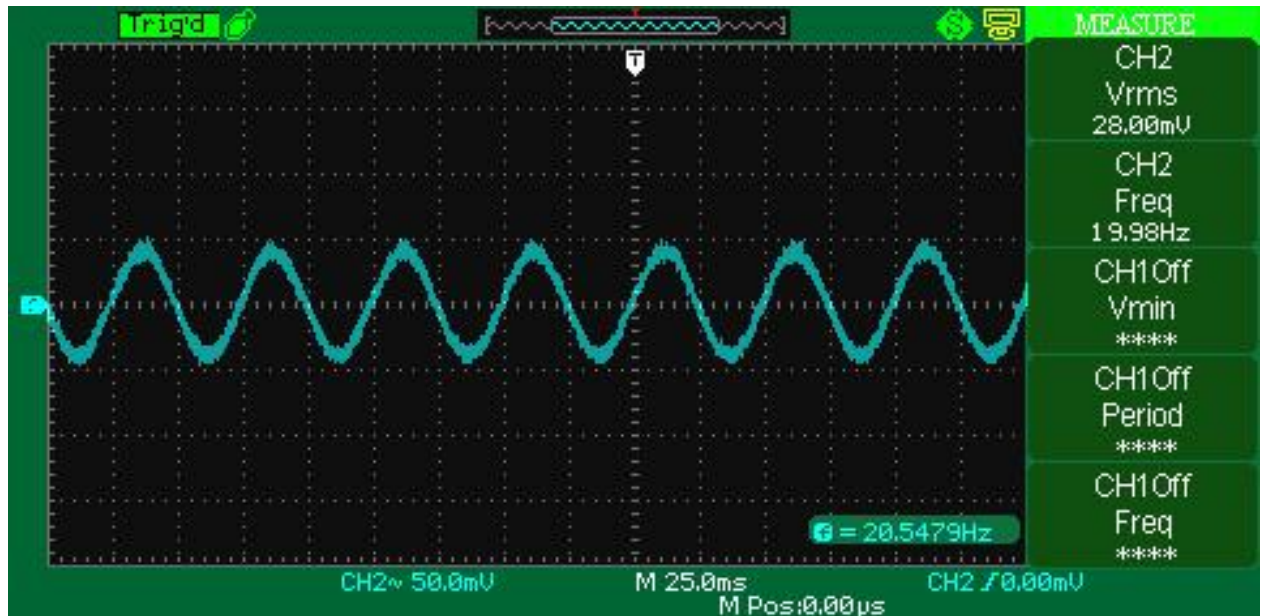

Fig.5 Voltage Across the Armature during the Measurement (28 mVrms, 20Hz)

As shown in Fig.5, RLC meter produce a very small voltage across the armature winding. Motor works with very higher voltages and currents. Verification of results taken from the previous measurement is done by analyzing the motor's current waveform. Armature current is recorded using a digital storage scope and a current probe. Fig.6, shows the current through armature winding.

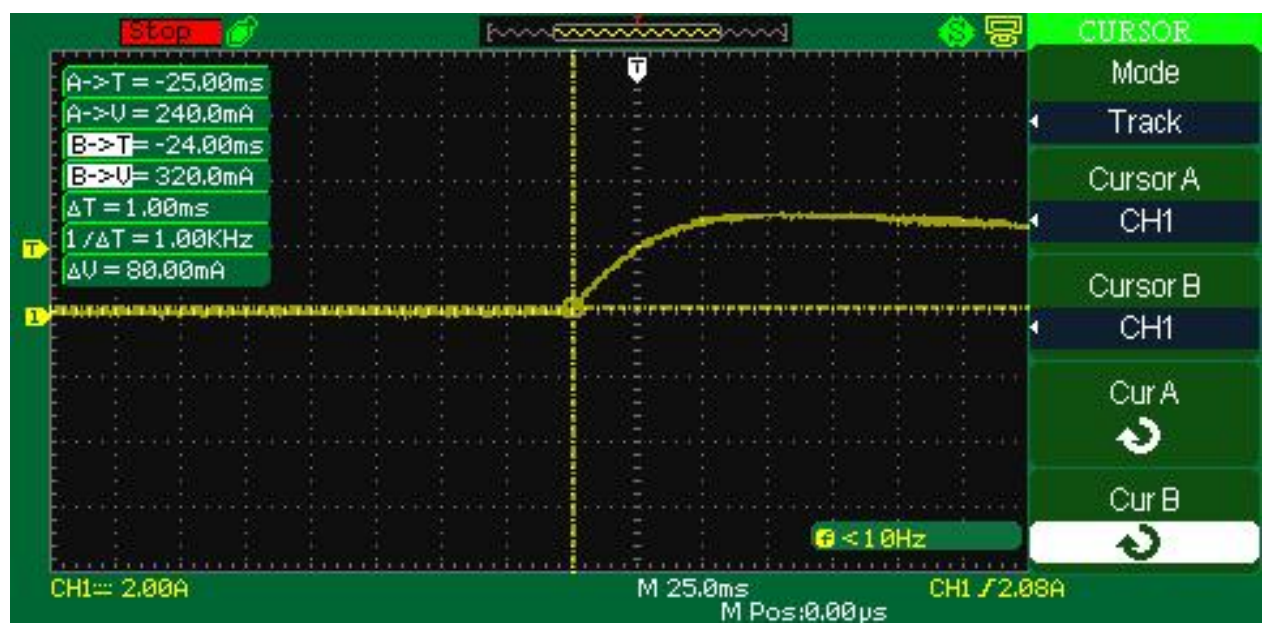

Fig.6 Current through Armature Winding (Varmature=20 V)

It can be easily shown that the slope around $t=0$ is equal to The armature current goes from $240 \mathrm{~mA}$ to $320 \mathrm{~mA}$ in $1 \mathrm{mS}$. Thus, the slope is . So, $\mathrm{L}=250 \mathrm{mH}$. Results shows that obtaining the electrical subsystems parameters using RLC meter does not lead to correct values of parameters.

\section{Conclusion}

DC motors have been used in different applications such as industrial automation, automotive, aero space and instrumentation. When motor is used in precious motion control systems, it's mechanical and electrical subsystems must be modeled carefully. Wide spread use of RLC meters may be tempt one to use RLC meter to measure motors parameters. This paper shows that using RLC meter does not lead to exact values of parameters so it must avoided.

\section{References}

[1] R. S. Ortigoza, J. N. A. Juárez, J. R. G. Sánchez, M. A. Cruz, V. M. H. Guzmán and H. Taud, Modeling and Experimental Validation of a Bidirectional DC/DC Buck Power Electronic ConverterDC Motor System, IEEE Latin America Transactions, 2017

[2] M. A. Akbar, T. Naniwa, Y. Taniai, Model Reference Adaptive Control for DC Motor Based on Simulink, International Annual Engineering Seminar (InAES), Yogyakarta, Indonesia, 2016 
[3] A.Tashakori, M. Ektesabi, N.Hosseinzadeh, "Modeling of BLDC Motor with Ideal BackEMF for Automotive Applications", Proceedings of the World Congress on Engineering, London, 2011

[4] V. Singh Patel, A.K. Pandey, Modeling and Performance Analysis of PID Controlled BLDC Motor and Different Schemes of PWM Controlled BLDC Motor, International Journal of Scientific and Research Publications, 2013

[5] A. E. Fitzgerald, Charles Kingsley and Stephan D. Umans, Electric machinery, Mc Graw-Hill, 2003.
[6] Stephan J. Chapman, Electric machinery fundamentals, Mc Graw-Hill, 2003.

[7] P. C. Sen, Principles of electric machines and power electronics, Wiley, 2013.

[8] Slobodan N Vukosavic, Electrical machines, Springer, 2012.

[9] Theoder Wildi, Electric machines, drives and power systems, Pearson, 2005.

[10] Charles I. Hubert, Electric machines: theory, operating applications and control, Pearson, 2001. 